\title{
13 \\ Building It for Them: Faculty-Centered Program Development and eManagement
}

\author{
Bonnie B. Mullinix
}

Monmouth University

This chapter documents the effectiveness of a responsive, multilevel, web-based system for identifying and responding to faculty interest and needs for training and development. A case-based description illustrates the advantages of using a web-facilitated approach to schedule sessions according to faculty interest and availability. From needs assessment survey, to session design and scheduling, to registration, communication, and monitoring of participation, to evaluation and feedback, this integrated system has proven effective in engaging faculty. Data collected over two years of program implementation is shared and implications for the design, facilitation, and evaluation of such approaches are considered.

\section{Vision, Direction, and Theoretical Foundations}

If you build it, will they come? Well, perhaps the answer is to build it for them, with each individual in mind, according to their wants, needs, and availability. This is what we did at Monmouth University as we designed and established the Instructional Technology Services' Faculty Resource Center in fall 2002. By taking advantage of the technological capabilities at hand, we created a system that allowed us to gather information and maintain both an individualized and collective vision of faculty needs and interests. This is what guides us as we continue forward. It is our touchstone and a practical and philosophical antidote to administrative tendencies to project faculty needs and sidetrack effective faculty development designs. Constructed to be 
locally responsive, our approach was informed by and built directly out of the collected knowledge base and experience of faculty developers and adult learning theorists and practitioners.

One of the greatest challenges for faculty development efforts has been ensuring faculty participation in workshops and other development offerings. Faculty development professionals regularly comment on the importance of building programs based on strategies of faculty engagement and a solid understanding of faculty needs (Fink, 1988; Hilsen \& Wadsworth, 1988; Sorcinelli, 1988). Adult learning theorists have long spoken to the fact that learner participation is enhanced by learning activities that address the interests and needs of adult learners in ways that highlight the relevance and immediate usefulness of information and skills (Brookfield, 1986, 1987; Knowles, 1970). By collecting data on interests and needs from faculty and constructing offerings that directly respond to these needs and interests, we address such concerns. By coordinating this information with data on faculty availability and cyclical instructional needs that emerge over the course of a semester we engage in a sophisticated scheduling process that enhances faculty participation and programmatic responsiveness. Through such strategies we take our process a step farther than Farr's (1988) recommendation for creating faculty development centers as resource centers that through a variety of resources might draw faculty into "what should be purely voluntary participation" (p. 35). Beyond providing an instructionally oriented structure and clear communication strategies, we work to design sessions that actively engage faculty in relevant and reflective activities, allowing them to critically situate new information within their own understanding, relationships, and teaching/learning approaches. In doing so, we draw on philosophical and practical advice from key educators over the past century (Dewey, 1916, 1938; Freire, 1984; Kolb, 1976, 1984). Further, our sessions are designed to model participatory instructional and learning methodologies and to create a safe, nurturing, and connected environment where action, risk, and challenge promotes learning (Meyers \& Jones, 1993; Silberman, 1998). Recognizing that our growth as scholar/practitioners is facilitated by reflective participation and immersion in learning experiences and communities of practice (AbdalHaqq, 1998; Freire, 1982, 1984; Knowles, 1970; Kolb, 1984; Merriam \& Caffarella, 1999), we attempt to facilitate such experiences and networks. We actively promote training series and follow-on sessions and as faculty networks and interest grows, we nurture emergent working groups that connect cohorts of faculty in continuing, reflective learning. 


\section{Origins and Context of the Case}

Recognizing that the ability of faculty developers to appreciate and ultimately replicate and adapt strategies requires knowledge of the grounded context of a case. The following narrative provides this vision and weaves a holistic view of how the center's faculty-centered approach unfolded.

Monmouth University is a midsize, comprehensive private university of approximately 6,000 students. The Faculty Resource Center (FRC), established in October 2002, represents Monmouth University's primary faculty training and support initiative on campus. In two years since the FRC began, the faculty has grown from 220 to 275 full-time faculty and from nearly 250 to more than 300 part-time/adjunct faculty. The full-time faculty complement had expanded by more than $34 \%$ in the previous five years, with $75 \%$ of the entire faculty having joined the university during the preceding eight years. The need for faculty support and development was (and remains) keen. The university confirmed this through a survey of faculty in 2001 as they began to explore the development of a Center for Excellence in Teaching and Learning (CETL).

In early 2002, faculty development existed on campus in a decentralized fashion as documented in an institutional assessment and preceding the initial design of CETL (Mullinix \& Sarsar, 2002). Beyond the traditional support of faculty scholarship, the strongest component of faculty development existed in Instructional Technology Services (ITS), which supported faculty through facilitation of online and web-enhanced Course Management Software, web design and classroom media, and computer lab and office desktop support services. To relate this to the broader historical context of faculty development, Sorcinelli, Austin, Eddy, and Beach (2006) might situate Monmouth in the Age of the Scholar and, with the emergence of the Faculty Resource Center, move it into the Age of the Teacher. While the current focus on outcomes assessment in higher education pushes the university quickly toward a focus on the learner, it may well be important for Monmouth, as for any university growing its faculty development program, to move progressively, if quickly, through each of the "Ages" of faculty development.

The key individuals responsible for the design of the FRC were the director of Instructional Technology (IT) and the newly appointed instructional design specialist. Their perspectives and complementary skills turned out to be critical resources in the design of the center. The IT director offered a strong background in education, a master's in instructional technology, and two years facilitating and building the Course Management System support on campus. With strengths in web design, presentation software, and multimedia, 
his technical knowledge and human resource management skills served to promote a creative, collaborative, and enabling environment within the IT unit. In addition, training as a $\mathrm{K}-12$ teacher and teaching courses in information technology and computer art at the university kept him keenly connected to the instructional realities on campus. While new to the ITS department, the instructional design specialist spent four years as faculty at the university, teaching fourteen courses in four departments across two schools, serving two years as a research chair, initiating faculty peer mentoring programs, supporting multiple grant and program initiatives, and promoting a campus-wide learning community for global understanding. With a doctorate in adult learning and education and 25 years experience as an educator and international educational consultant, the instructional design specialist brought a wealth of ideas for responsive, participatory, and collaborative program design as well as a well-grounded faculty perspective. Her focus at Monmouth became faculty development and support. Her close collaboration with the university's Office of Academic Program Initiatives and its associate vice president to survey faculty and design CETL further informed her knowledge of faculty needs and the institutional context.

This team began by acknowledging the needs and constraints of the environment and resources, recognizing the need for gathering more information directly from faculty that would guide their efforts. In their first month together, they took stock and shared their thoughts on potential, needs, and possibilities. Faculty were increasingly asking for orientation to technology and assistance integrating technology into their teaching. It was also clear that support for instructional design and improving the teaching and learning environment was, by in large, not available on campus. So they challenged themselves to create such a support structure, building on their knowledge of best practices in adult learning and faculty development, tapping integrative technology potential, and working within the contextual realities and existing institutional constraints and resources. With the approval of the ITS department leadership and the provost, they moved forward to create a Faculty Resource Center within ITS, all the while keeping their design focus learningdriven, needs-based, and faculty-centered.

These design goals inspired and required that they begin with a survey of faculty needs, interests, and availability-the core information needed to design responsive offerings that can be scheduled at convenient times. Realizing that their base within IT made it both convenient and appropriate to leverage the talent and ability of their Web Factory and IT unit colleagues, they created an online survey. This served as the beginning of a web-based management system encouraging the collection and swift analysis of key 
data. The original survey solicited faculty needs and interests regarding instructional design and technology (across eight faculty role-focused categories), personal availability, and expertise. Once posted to the web, faculty were informed via email of the survey's availability and encouraged to complete either the hyperlinked online form or an attached copy. While hardcopies were not distributed, the accommodation for the less technologically savvy was to allow the attached copies to be printed, completed, and returned by mail or email. Faculty were promised that if survey responses were received within a week and a half, their input and information would guide the design of the Faculty Resource Center and be used to prioritize the first round of FRC offerings.

The web-based survey proved extremely powerful and inspiring, and the survey information compiled clearly indicated priority topics for faculty. Those topics receiving the highest scores became the FRC offerings that were created and offered first. Sessions with less of an interest/need were slated to be offered later in the semester or academic year (see Table 13.1).

TABLE 13.1

Distribution of Needs/Interest Survey Across FRC Training Series Categories

\begin{tabular}{clc}
\hline \# Responses & Survey Categories (FRC Training Series) & $\begin{array}{c}\text { \# Sessions/ } \\
\text { Items }\end{array}$ \\
\hline 198 & Organizing, managing, and communicating & 6 \\
217 & Preparing for class —designing courses and sessions & 5 \\
179 & Designing class materials and multimedia presentations & $4-7$ \\
111 & In the classroom & 3 \\
287 & Class on the web & 9 \\
169 & Evaluation and assessment & 4 \\
190 & Web design and publishing & $4-5$ \\
87 & Beyond the classroom-peer support for research and scholarship & \\
& supporting teaching and learning & 4 \\
\hline 1,438 & Total responses from 149 respondents to & $39-43$ \\
\hline
\end{tabular}

A second scheduling criterion, which helped to determine the approximate order of offerings, was the immediacy of need extrapolated from the common instructional cycle within a semester (e.g., sessions on generating 
course lists in support of organization or active-learning techniques were generally scheduled before sessions oriented toward evaluation). With the support of the IT Web Factory, a schedule overlay applet was developed to take the survey data and display all individuals interested in a topic across a week-block schedule. Precise scheduling of day and hour for priority sessions could then be determined by identifying the schedule blocks where the largest numbers of faculty were available. Once scheduled, these same individuals received priority registration in the sessions that had been developed with them in mind. This proactive outreach helped to ensure a base participation for each session planned that maximized the small physical space of the FRC (accommodating only 6-12 participants, depending on the need for wireless laptop access).

The developing web-based management system included automated communications that sent messages confirming registration into the system and registration into sessions as well as messages when sessions were rescheduled or canceled. The full complement of offerings was then shared with fulland part-time faculty through email and posted to the FRC web site, at which point all faculty were invited to register themselves for sessions through the web-based system. The web site was established to share current offerings categorized by faculty role-oriented series. It helped to document the FRC's activities, listing dates and times and offering descriptions and a growing complement of handouts and session guides.

Following sessions, participants' status was updated to "attended" (or "cancelled" or "no show") in the system and each received a thank-you email soliciting feedback on the session, what was learned/what was useful, how they planned to use/apply what they learned, and how the session could be improved.

It was clear that this approach to developing a faculty-oriented FRC was well received. The reward was steady participation and clearly articulated appreciation. Seventy-two faculty (approximately $13 \%$ of the entire faculty population) completed the online survey during the first year. This moved up to 128 responses by the second year of the FRC (representing a $22 \%$ response/participation rate for the overall faculty and a $49 \%$ response rate for faculty participating in the FRC offerings). By December 2004, the number of responses on the survey was 149 . By the end of our first semester (lasting approximately two months), the FRC had offered 27 sessions covering 17 unique topics. By the end of its inaugural year, the FRC had offered 82 sessions to more than 400 faculty participants. By the end of the second year, this expanded to 115 events for approximately 408 attendees. By December 2004, the total cumulative offerings of the FRC's two and a half years was 240 events 
covering 43 unique topics for more than 850 faculty participants and reaching $46 \%$ of the total faculty at Monmouth (for greater detail on events and participation rates, see Figures 13.1 and 13.2; for detail on the representative distribution across positions, see Table 13.2, shown later).

At the end of the first academic year, the FRC coordinators created another web-based applet that allowed them to use the data in the FRC management system to display individual participation and create letters of acknowledgement for each of the faculty participants, documenting sessions attended as well as officially noting the faculty member's commitment to improving their facilitation of learning. These letters are signed by the FRC coordinator-facilitators and distributed directly to faculty members at the beginning of each academic year so they may share them with colleagues, chairs, or deans, and/or include them in their promotion and tenure dossiers. This approach to sharing FRC-witnessed documentation of their participation directly with faculty is in keeping with a process that encourages faculty control and empowerment in professional development and respects the need for confidentiality in faculty development. Participant names are not shared with the administration by the FRC; rather descriptive and comparative statistics (as embedded herein) are tracked and shared on a semiannual basis and as requested.

\section{Approach, Components, and Processes}

The FRC team keeps its focus on faculty by directly and regularly referencing faculty data, maintaining proactive and supportive communication strategies, and offering hands-on sessions that situate skills, information, and technologies firmly within the teaching and learning arena and clearly associated with faculty roles and responsibilities. The following sections describe how and why we do what we do and how we see each of our efforts as faculty-centered. It touches on the following:

- Faculty needs and interest assessment

- Design of offerings

- Prioritization of offerings

- Scheduling of offerings

- Communication of offerings

- Participant registration 
- Communication with registered FRC participants

- Recognition and utilization of faculty expertise

- Monitoring, evaluation, and reporting

- Acknowledging faculty participation

At the core of this approach is a responsive, technology-facilitated, multilevel, web-based system that includes a faculty interest/needs assessment survey with a dynamic analysis interface and a registration system with automated communication that helps monitor participation and solicits evaluation and feedback. This approach has helped to underscore in the minds of faculty the direct relationship between their needs and the center's offerings. We have found that coordinating data on faculty needs with availability and cyclical instructional needs that emerge over a semester results in a sophisticated scheduling process that enhances faculty participation. While we are still working on improving our web-based system, it has drawn on our collective creativity and shows great promise as a management tool. Indeed, we have received a POD (Professional and Organizational Development Network in Higher Education) grant to allow us to enhance it to a point where we can share it with other faculty developers. While any information-based system takes time to manage (Plank, Kalish, Rohdieck, \& Harper, 2005), there is no doubt that the web-based nature and automated features of this system results in an ultimate effectiveness in both time and cost.

The following provides a description of each web-based component of our e-management system and a link to the associated tool.

\section{r.Faculty Needs and Interest Assessment}

This is the foundation of our faculty-centered approach and accomplished through an online survey that gathers information about individual faculty interests, needs and availability (following the initial generic survey, the questions were updated to reflect actual offerings and serve as a preview of the full range of FRC sessions/series). Tool: Faculty Interest and Needs Assessment Survey (http://its.monmouth.edu/OnlineSurvey/its/faculty_needs/).

\section{:Design of Offerings}

Responding to recognizable roles and responsibilities of faculty, offerings include instructionally oriented and learning-centered session series that focus on design in support of learning and technology use and are developed to fit faculty timeframes and desires. Offerings fit within eight robust and 
inclusive categories: organizing, managing, and communicating; preparing for class-designing courses and sessions; designing class materials and multimedia presentations; in the classroom; class on the web; evaluation and assessment; web design and publishing; beyond the classroom-peer support for research and scholarship supporting teaching and learning. Tool: List of offerings (http://its.monmouth.edu/FacultyResourceCenter/FRC-Training SeriesList.htm).

\section{c Prioritization of Offerings}

Offerings are prioritized by viewing faculty survey responses through a webbased dynamic interface that displays numbers of responses with links to actual respondent availability distributed across a schedule of session time blocks in a week (we encourage faculty to update their availability each semester and whenever their schedules change). Tool: See a sample display page at http://its.monmouth.edu/trainingGuest/survey/results/answertable.asp.

\section{Scheduling of Offerings}

By overlaying the prioritized offerings onto semester instructional cycles and reviewing faculty availability, we are able to schedule sessions for a cohort of participants, registering individuals who expressed interest in a specific topic and availability at a common time. Tool: See the FRC home page (http://www.monmouth.edu/frc) and the FRC registration page (http://its.monmouth.edu/training/trainingForm.asp).

\section{Communication of Offerings}

The schedule of offerings is communicated through multiple mechanisms. It is posted online at the Faculty Resource Center home page and email communications summarizing current offerings are sent to all faculty with links to this page and the online registration system. Tool: FRC home page (http://www.monmouth.edu/frc).

\section{Participant Registration}

An online registration system that allows faculty to directly register for (and cancel out from) sessions of interest and FRC administrators to facilitate the same. Tool: FRC registration page (http://its.monmouth.edu/training/training Form.asp). 


\section{Communication With Registered FRC Participants}

The registration system's automated communication seamlessly informs participants of sessions when they register. Once marked as attended, the system acknowledges their participation and solicits feedback. Tool: See sample emails at http://its.monmouth.edu/trainingGuest/frc-sicem.html.

\section{Recognition and Utilization of Faculty Expertise}

An important part of faculty-centered development, we strive to identify and utilize faculty expertise. We begin by soliciting faculty interest in sharing their skills in the FRC survey, encouraging faculty to facilitate FRC sessions, and sponsoring events to highlight faculty innovations in teaching and learning. Tool: Homegrown Innovations in Teaching and Learning (http://its.monmouth .edu/facultyresourcecenter/HomegrownShowcase2004-Program.htm).

\section{Monitoring and Reporting}

We maintain a tracking system to monitor and record faculty participation levels to facilitate planning, research, evaluation, and reporting. Tool: FRC resigtration systems reports page (http://its.monmouth.edu/training Guest/admin.asp [login: guest; password: guest]).

\section{- Acknowledging Foculty Participation}

We have developed an applet that allows us to produce personalized letters of recognition/acknowledgement for participants through a merged narrative that draws directly from our management database and is linked off of a webbased listing of participant attendance. Sensitive to the delicate balance between faculty confidentiality concerns and public acknowledgment of faculty development, we have opted to send these letters directly to faculty at the end of the academic year and allow/encourage them to disseminate and use them as they feel appropriate (with chairs, deans, for tenure and promotion reviews, etc.). Tool: See a sample page and letter at http://its.monmouth .edu/trainingGuest/frc-sicem.html.

\section{Data Analysis Strategies Informing Reflective Practice}

Faculty needs and interests drove not only the FRC and participation in its offerings but also the survey response and participation rates. Descriptive statistical analysis of both datasets were used to confirm that this faculty selfselection mechanism produced a remarkably representative sample of the 
university faculty complement with respect to both survey respondents and FRC event participants. In analyzing faculty feedback on the importance, impact, and design of the FRC and its offerings, grounded theory informed an analysis strategy that relied on capturing emergent themes from written feedback on sessions and allowing for their growth and ongoing validation (Strauss \& Corbin, 1998). Periodic informal and formal discussions served as an inductive base from which to identify effective and ineffective practice, and themes of topic impact were then further expanded and identified through document analysis (of email, online surveys, and handwritten evaluation forms). Data analysis was further enhanced and influenced by use of NVivo Qualitative Software . Joint and cross-coding approaches were utilized by the researchers to increase validity (Richards, 1999) and generate multiple free- and tree-noded categories supported by quotations and emergent analysis. While results from the qualitative analysis of narrative evaluation and feedback findings is not explicitly illustrated here, it has proven an important source of formative and inspirational guidance.

\section{: Patterns of Participation, Findings, and Considerations}

It has been important to build in time for analysis, documentation, and dissemination of the statistical participation patterns, particularly to ensure their inclusion in formative development of the FRC. Visual and tabular data had been prepared and shared both with university administrators through regular reporting and through professional presentations to colleagues regionally and nationally (Mullinix, 2004; Mullinix \& Harr, 2003, 2004; Mullinix \& Savoth, 2004). Figures 13.1 and 13.2 show, respectively, the relationship between total and unique sessions and events offered over time and the distribution of faculty in terms of cumulative and unique attendees.

In the first year, participation encompassed approximately $43 \%$ of the university's full-time faculty and more than $18 \%$ of part-time faculty from a full cross-section of departments and schools. By the end of the second year, the FRC was able to increase this participation rate to $46 \%$ and $26 \%$, respectively, even in the face of decreasing human, physical, and financial resources. The breakdown of faculty participation among those actively engaged in FRC sessions by the end of 2004 was distributed as follows: $63 \%$ full-time faculty (with $40 \%$ tenure-track faculty) and $30 \%$ part-time faculty. The percentage representation of FRC participants across faculty categories is remarkably representative of the percentage representation of Monmouth University faculty overall (see Table 13.2). 
FIGURE 13.1

FRC Events and Topics

Fall 2002-Fall 2004

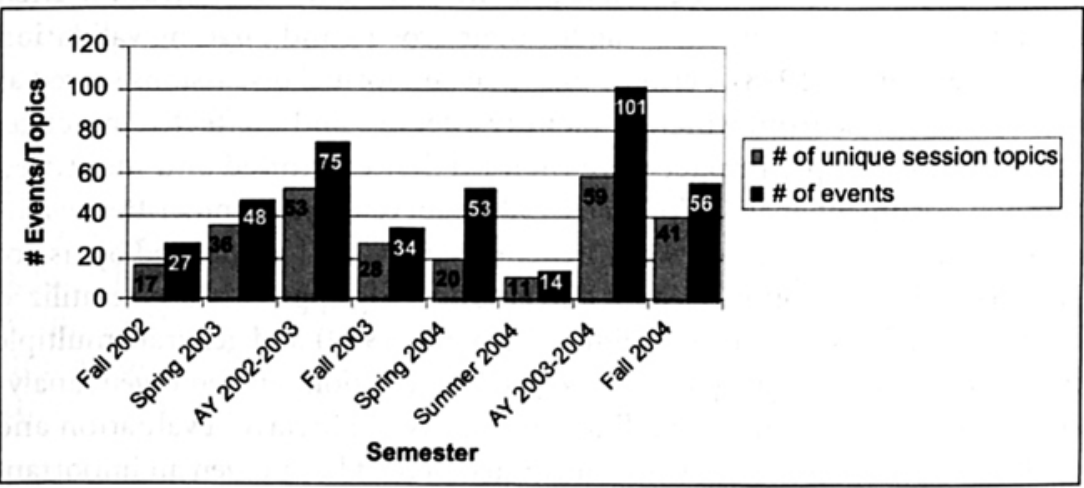

FIGURE 13.2

FRC Event/Session Participation

Fall 2002-Fall 2004

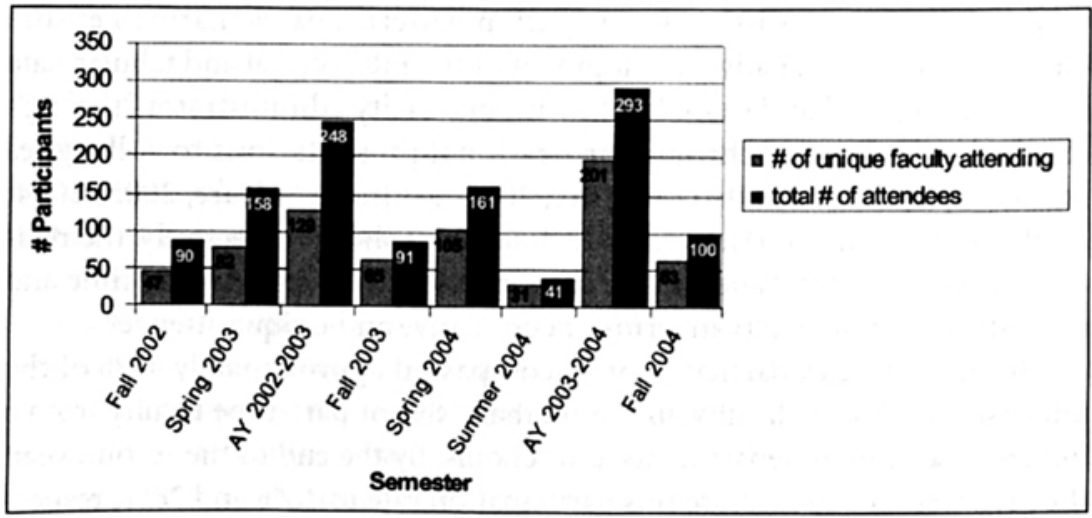

\section{Limitations of the Approach and System}

As with every initiative, there exist limitations to be acknowledged and addressed. For each limitation identified, an attempt was made to shift focus and utilize it as an advantage. Utilization of the dynamic web-based data to schedule FRC sessions was sufficiently effective to produce a profile of FRC offerings that mirrored closely the training needs profile resulting from the 
TABLE 13.2

Faculty Participation Distributions

\begin{tabular}{|c|c|c|c|c|}
\hline & $\begin{array}{c}\text { FRC } \\
\text { Participants }\end{array}$ & $\begin{array}{l}\text { Percentage } \\
\text { of FRC } \\
\text { Participants }\end{array}$ & $\begin{array}{c}\text { Percentage } \\
\text { of MU } \\
\text { Faculty }\end{array}$ & $\begin{array}{c}\text { Total } \\
\text { MU Faculty }\end{array}$ \\
\hline Part-Time Faculty & 79 & $30 \%$ & $26 \%$ & 306 \\
\hline Part-time/adjunct & 60 & $22 \%$ & & 300 \\
\hline Faculty (P-T)/admin. & 19 & $7 \%$ & & 6 \\
\hline Full-Time Faculty & 188 & $63 \%$ & $61 \%$ & 274 \\
\hline Full-time instructor & 44 & $16 \%$ & & 72 \\
\hline Visiting assistant professor & 13 & $5 \%$ & & 3 \\
\hline Specialist professor* & 4 & $1 \%$ & & 12 \\
\hline Tenure-Track Faculty & 127 & $40 \%$ & $57 \%$ & 187 \\
\hline Assistant professor & 47 & $18 \%$ & & 58 \\
\hline Associate professor & 43 & $16 \%$ & & 86 \\
\hline Professor & 17 & $6 \%$ & & 43 \\
\hline Guest/Admin. & 20 & $7 \%$ & & \\
\hline Totals & 267 & 一 & $46 \%$ & 580 \\
\hline \multicolumn{5}{|l|}{ Inclusive of: } \\
\hline Chairs & 14 & $5 \%$ & $61 \%$ & 23 \\
\hline Deans/associate, assistant deans & 5 & $2 \%$ & $26 \%$ & 19 \\
\hline Directors & 3 & $1 \%$ & - & - \\
\hline
\end{tabular}

"Specialist professors are faculty hired with unique qualifications and specific experience for five-year periods.

faculty needs and interest survey. While some may consider the subjective selfanalysis and reporting approach of a needs assessment survey an inferior baseline data source, as an initial catalyst to encourage participation we found it to be a strength. Another potential limitation of the survey could be its online and email delivery, which may have limited response from certain quarters. However, the fact that the FRC was situated within the Instructional Technology Services department of the university justified and supported this strategy as did the intended dynamic use of the information (and interest in limiting costs associated with ongoing implementation of the system overall). Online results and the creation of the dynamic web-based analysis interface allowed 
for the easy, ongoing integration of data as new faculty complete the survey over time. Posting survey access on the FRC web page and presenting it as an integrated component of participating in FRC sessions helps to encourage continued submissions.

A limitation of this system may well be the importance of its proactive engagement of faculty and continuing focus on faculty-identified topics. Contextual constraints placed on the FRC during academic year 2003-2004 have resulted in lower participation rates among faculty. Early in the year, an increasing number of sessions driven by administrator recommendation rather than faculty request have inflated the number of sessions offered in certain categories that were neither priority response items nor integral to the FRC (i.e., they were focused on technical training on generic computer use rather than being instructionally oriented). Though offered, few faculty attended these sessions. In addition, decreased opportunities for active outreach to faculty-the loss of high-level web page links, a buried web site, fewer public outreach opportunities, a decreasing focus on FRC team priority registration of faculty into sessions, and less personal encouragement of faculty to participate-have also impacted participation.

\section{Impact, Advantages, and Contributions}

Ultimately, this approach is nothing more than good learning facilitation practice grounded in learning theory and research. By clearly and strategically embedding these elements in our practice we create an effective program and model effective practice with the intent that faculty may replicate and integrate the following as they work to enhance their facilitation of learning:

- Base their curriculum on participant interests and needs

- Design sessions that actively engage participants in learning

- Gather feedback and suggestions for improvement

- Modify their approach and techniques appropriately and continue to monitor and improve their practice

Using faculty interests, needs, and availability to directly design events and sessions, prioritize offerings, and determine appropriate schedules allows for an increased sense of ownership as well as increased participation levels among faculty. This approach has helped to underscore in the minds of faculty the direct relationship between their needs and the center's offerings. We have found that coordinating data on faculty needs with availability and 
cyclical instructional needs that emerge over the course of a semester results in a sophisticated scheduling process that enhances faculty participation.

Each element of this system offers its own acknowledgement of and contribution to faculty development strategies. The needs-based survey tool was compiled through a review of offerings by centers for teaching and learning across the nation and based on an extensive, categorized list of training topics. These overarching categories were then woven into the FRC's structure and have proven robust over two years of use. They may well prove useful for others who wish to establish new faculty support programs or evaluate existing centers for teaching and learning. Such responsive faculty development designs hold promise for encouraging meaningful participation by clearly highlighting and acknowledging the faculty-driven nature of the program and its offerings. In addition, they offer a structure that directly addresses and counteracts the longstanding problem of low-level participation by faculty by tailoring offerings directly to needs, interests, and time constraints. Our experience has shown that when you build it for them, faculty will come.

\section{Implications for Growth and Future Practice}

POD has proven a nurturing and enabling scholarly environment for the growth and innovative expansion of a place such as the FRC and such a webbased system. Indeed, this chapter has grown from and built on several presentations, workshops, and/or papers presented at POD conferences (Mullinix \& Harr, 2003; Mullinix \& Savoth, 2004) and POD's sister association, the Faculty Training, Evaluation, and Development Special Interest Group of the American Educational Research Association (Mullinix \& Harr, 2004).

While presenting and receiving their Bright Idea Award from POD, Mullinix and Harr noted significant interest in their approach and received encouragement to develop the web-based management system so that faculty developers at other institutions might make use of it. A grant was submitted to POD with the support of key POD members who saw promise in the system. Mary Deane Sorcinelli and Barbara Millis offered up their institutions' Centers for Teaching and Learning as collaborating partners. While the instructional technology area of Monmouth University underwent substantial reorganizations from May through early 2005, the grant was accepted in October 2004. Interest has continued to grow and several regional community colleges have expressed interest in participating in the early testing of the system. Work has begun on developing the web-based e-management system 
into a more modifiable and user-friendly version that can be shared with interested POD member institutions in higher education.

PIECES, as we have named our next-generation system, embeds the key components within its name: Participant Information, Event, and Communication E-Management System. It also represents the vision that we have for the flexible implementation of this system, as we hope to allow faculty developers to pick and choose the "pieces" of PIECES that best fit their needs and contexts. The ultimate goal will be to build on the strengths of this system and encourage data-referenced design and evaluation of faculty development in higher education.

Evaluation is a broad umbrella that easily spans the distance from needs assessment to formative, summative, and impact evaluation. The needs assessment and formative evaluation pieces provide us with the information needed to build a responsive program that can increasingly and appropriately meet specific faculty needs. Summative and impact evaluation provide us with the information we need to chart outcomes and progress, remain on track, and help everyone involved to understand how we are making a difference.

Ultimately, we believe that the power of this faculty needs and interestcentered approach lies in its ability to help individual faculty members identify and act on their desire for skills and knowledge development, directly informing their abilities as learning facilitators and designers. As initial findings indicate, when self-motivated and institutionally supported, faculty feel empowered to take risks in instructional design and practice. One of the best ways to support faculty on this journey is to design learning opportunities directly based on their needs and interests. Our integrated system provides the tools to do this and takes the next step toward providing the summative and impact data that can help document and ensure sustainability of faculty development efforts.

\section{References}

Abdal-Haqq, 1. (1998). Professional development schools: Weighing the evidence. Thousand Oaks, CA: Corwin Press.

Brookfield, S. D. (1986). Understanding and facilitating adult learning. San Francisco, CA: Jossey-Bass.

Brookfield, S. D. (1987). Developing critical thinkers. San Francisco, CA: Jossey-Bass.

Dewey, J. (1916). Democracy and education: An introduction to the philosophy of education. New York, NY: Macmillan. 
Dewey, J. (1938). Experience and education. New York, NY: Touchstone.

Farr, G. (1988). Faculty development centers as resource centers. In E. C. Wadsworth (Ed.), A handbook for new practitioners (pp. 35-38). Stillwater, OK: New Forums Press and Professional and Organizational Development Network in Higher Education.

Fink, L. D. (1988). Establishing an instructional development program. In E. C. Wadsworth (Ed.), A handbook for new practitioners (pp. 21-25). Stillwater, OK: New Forums Press and Professional and Organizational Development Network in Higher Education.

Freire, P. (1982). Creating alternative research methods: Learning it by doing it. In B. Hall, A. Gillette, \& R. Tandon (Eds.), Creating knowledge: A monopoly (pp. 29-37). New Delhi, India: Society for Participatory Research in Asia.

Freire, P. (1984). Pedagogy of the oppressed. New York, NY: Continuum.

Hilsen, L., \& Wadsworth, E. C. (1988). Staging successful workshops. In E. C. Wadsworth (Ed.), A handbook for new practitioners (pp. 45-52). Stillwater, OK: New Forums Press and Professional and Organizational Development Network in Higher Education.

Knowles, M. S. (1970). The modern practice of adult education: Andragogy versus pedagogy. New York, NY: Associated Press.

Kolb, D. A. (1976). The learning style inventory: Technical manual. Boston, MA: McBer.

Kolb, D. A. (1984). Experiential learning: Experience as the source of learning and development. Englewood Cliffs, NJ: Prentice-Hall.

Merriam, S. B., \& Caffarella, R. S. (1999). Learning in adulthood: A comprehensive guide (2nd ed.). San Francisco, CA: Josscy-Bass.

Meyers, C., \& Jones, T. B. (1993). Promoting active learning: Strategies for the college classroom. San Francisco, CA: Jossey-Bass.

Mullinix, B. B. (2004). Tapping technology to facilitate a faculty-centered approach to faculty development. Paper presented at the 2nd annual Technology in Education Conference, Plainsboro, NJ.

Mullinix, B. B., \& Harr, C. (2003). Faculty-centered program development. Paper presented as Bright Idea Award Winner at the 28th annual meeting of the Professional and Organizational Development Network in Higher Education, Denver, $\mathrm{CO}$. 
Mullinix, B. B., \& Harr, C. (2004). Build it for them, they will come: Interest-based and scheduled faculty development. Paper presented at the 84th annual meeting of the American Educational Research Association, San Diego, CA.

Mullinix, B. B., \& Sarsar, S. (2002). Institutional proposal for establishing a center for excellence in teaching and learning at Monmouth University [Internal report]. West Long Branch, NJ: Monmouth University, Office of Academic Program Initiatives.

Mullinix, B. B., \& Savoth, W. (2004). Technological tools of our trade: Managing and assessing faculty development. Pre-conference workshop at the 29 th annual meeting of the Professional and Organizational Development Network in Higher Education, Montreal, Canada.

Plank, K. M., Kalish, A., Rohdieck, S. V., \& Harper, K. A. (2005). A vision beyond measurement: Creating an integrated data system for teaching centers. In S. Chadwick-Blossey \& D. R. Robertson (Eds.), To improve the academy: Vol. 23. Resources for faculty, instructional, and organizational development (pp. 173-190). Bolton, MA: Anker.

Richards, L. (1999). Using NVivo in qualitative research. Thousand Oaks, CA: Sage.

Silberman, M. (1998). Active training: A handbook of techniques, designs, case examples, and tips (2nd ed.). New York, NY: Wiley.

Sorcinelli, M. D. (1988). Encouraging excellence: Long-range planning for faculty development. In E. C. Wadsworth (Ed.), A handbook for new practitioners (pp. 27-31). Stillwater, OK: New Forums Press and Professional and Organizational Development Network in Higher Education.

Sorcinelli, M. D., Austin, A. E., Eddy, P. L., \& Beach, A. L. (2006). Creating the future of faculty development: Learning from the past, understanding the present. Bolton, MA: Anker.

Strauss, A., \& Corbin, J. (1998). Basics of qualitative research: Techniques and procedures for developing grounded theory (2nd ed.). Thousand Oaks, CA: Sage. 